\title{
Evaluation of antifungal activity of gel based hand wash using Camellia sinensis (Green tea) and Myristica fragrans (Nutmeg)
}

\author{
Jolly Mariam Johny*1, P.Saravanakumari ${ }^{2}$ \\ ${ }^{I}$ Department of Microbiology, Bharathiar University, Coimbatore, Tamil Nadu, India \\ ${ }^{2}$ Department of Biotechnology, Sree Narayana Guru College, Coimbatore, Tamil Nadu, India
}

\begin{abstract}
Hydro-ethanolic extracts of Camellia sinensis (Green tea) and Myristica fragrans (Nutmeg) were prepared and phytochemical screening analysis was done. Using Dr. Duke's phytochemical and ethanobotanical databases, the bioactive compounds pooled out were used as ingredients in the formulated gel based hand wash. In vitro antifungal assay of extracts was performed; its MIC values were estimated and compared with antifungal agents. A gel based hand wash was formulated using Camellia sinensis (Green tea) and Myristica fragrans (Nutmeg), and evaluated by physical parameters like, colour, odour, spreadability, $p H$ and overall appearance of the formulation. The present study also assess the antifungal activity of Camellia sinensis (Green tea) and Myristica fragrans (Nutmeg) handwash gel against target fungal species.
\end{abstract}

Keywords - Camellia sinensis (Green tea), Dr. Duke's Phytochemical and Ethanobotanical databases, Hydroethanolic extracts, In vitro antifungal activity, Myristica fragrans (Nutmeg)

\section{Introduction}

Higher plants have been shown to be potential source for the new antimicrobial and cosmeceutical agents ${ }^{[1]}$. Plant extract have a potential as antimicrobial compounds against several pathogenic microorganisms which cause infectious disease and resistance towards synthetic drugs. One of the less unexplored source are spices which traditionally known as good therapeutics ${ }^{[2]}$. Chemical tests are carried out on the hydro-ethanol extracts using standard procedures to identify the constituents ${ }^{[3]}$. Camellia sinensis (Green tea) belongs to the family Theaceae, and is one of the most widely consumed beverages in the world. It is prepared by picking, lightly steaming, and allowing the leaves to dry ${ }^{[4]}$. Green tea contains other agents that have chemo preventive activities. These include caffeine, flavandiols, flavanoids, phenolic acids as well as the alkaloids theobromine and theophylline ${ }^{[5]}$. Myristica fragrans (Nutmeg) belongs to Myristicaceae which has stimulant, carminative, and astringent properties. Its hallucinogenic properties are ascribed to the aromatic ethers, myristicin, elemicin and safrole ${ }^{[6]}$. Nutmeg oils are anti-oxidant agents, and they also exhibit strong antimicrobial and insecticidal properties ${ }^{[7]}$. Both in vitro and in vivo studies have resulted in a wide array of pharmacological actions attributed to nutmeg including analgesic, antifungal ${ }^{[8]}$, antimicrobial ${ }^{[9]}$, anti-inflammatory, as well as hepatoprotective activities. Botanical compounds used as active ingredients incorporated into topical formulations for dermatologic and cosmetic applications include: olive oil, chamomile, colloidal oatmeal, oat kernel extract, feverfew, acai bery, coffee berry, curcumin, pomegranate, licorice, paper mulberry, green tea, nutmeg, and resveratrol considered ${ }^{[10]}$. Hand washing "remains the single most effective and cost-efficient method for preventing and reducing the transmission of nosocomial infections".

The present study indicates the antifungal assessment and MIC of the formulated gel based handwash using Camellia sinensis (Green Tea) and Myristica fragrans (Nutmeg) against target fungal species including Candida albicans, Candida tropicalis, Fusarium species, Aspergillus species, and Pencillum species. Also, the known and reported phytochemicals with its bioactive properties about Camellia sinensis (Green Tea) and Myristica fragrans (Nutmeg) were retrieved from Dr. Duke's Phytochemical and Ethanoboanical databases ${ }^{[11]}$.

\section{Materials and Methods}

1.1 Collection, Phytochemical screening, and Processing of Plant material

Camellia sinensis (Green tea) was procured from T.Stanes \& Company Limited, Coimbatore District and Myristica fragrans (Nutmeg) was collected from the Changanacherry taluk of Kottayam District, and were authenticated in Tamil Nadu Agricultural University. About $1.5 \mathrm{~kg}$ of fresh plants were collected in bulk, washed under running tap water to remove adhering dust, dried under shade and powdered. The hydro-ethanolic extract was prepared using water by simple maceration technique ${ }^{[12]}$. About $50 \mathrm{~g}$ of the plant materials was extracted with $250 \mathrm{~mL}$ of hydro-ethanol (1:1) with occasional shaking for about 48 hours at room temperature $22-24{ }^{\circ} \mathrm{C}$, and filtered. The filtrate was evaporated to dryness. Phytochemical screening test ${ }^{[13]}$ and retrieval of known bioactive components using Dr.Duke's Phytochemical and Ethanobotanical Databases was done. 


\subsection{Isolation, Identification of Fungal isolates, and Invitro Antifungal Assay}

Aspergillus niger (MTCC 1344), Fusarium species (MTCC 6343), Pencillium species (MTCC 161), Candida albicans (MTCC 183), and Candida tropicalis (MTCC 184) were used for the study. The cultures were inoculated on to Sabourand's Dextrose Agar, and incubated at room temperature for yeast species for $24-48$ hours, and five days for fungal growth. The morphological and biochemical identification methods were performed. Hydro-ethanolic extracts of Camellia sinensis and Myristica fragrans were subjected to perform in vitro antifungal assay using Agar well diffusion method ${ }^{[14]}$ against selected fungal isolates. The results were observed and recorded. It was compared with standard antifungal agent Ketaconazole. The minimum inhibitory concentrations of extracts of Camellia sinensis (Green tea) and Myristica fragrans (Nutmeg) were found using Broth Dilution assay method ${ }^{[15]}$. The tubes were examined for visible turbidity after incubation. The turbidity was measured in terms of optical density at $620 \mathrm{~nm}$ and the results were tabulated.

\subsection{Formulation of hand wash gel using extracts of Camellia sinensis (Green tea) and} Myristica fragrans (Nutmeg)

2.3.1. Preparation of gel base as per Ingredient Chart $1^{\text {[16], [17], [18] }}$

Ingredient Chart 1

\begin{tabular}{|l|l|l|}
\hline S.No & Ingredients & Quantity taken \\
\hline 1. & Carbopol-940 & $1 \mathrm{~g}$ \\
\hline 2. & Purified water & $100 \mathrm{ml}$ \\
\hline 3. & Triethanolamine & $\begin{array}{l}\text { q.s. to neutralize gel } \\
\text { base }\end{array}$ \\
\hline
\end{tabular}

Carbopol-940 was soaked in water overnight (12 hours). Then the swelled polymer was stirred using a mechanical stirrer to ensure the uniform dispersion of the polymer. The $\mathrm{pH}$ was adjusted to 7.0 using Triethanolamine. Then this base was used to incorporate medicaments or active ingredients Camellia sinensis (Green tea) and Myristica fragrans (Nutmeg) to prepare a formulation of hand wash gel as per Ingredient chart 2. The formulation was undergone organoleptical evaluation. Invitro antifungal assay of the formulated had wash gel against the selected fungal isolates were then performed

Ingredient chart 2

\begin{tabular}{|l|c|}
\hline \multicolumn{1}{|c|}{ Ingredients } & Quantity \\
\hline Gel base & $30 \mathrm{~g}$ \\
\hline Camellia sinensis & $2 \%$ \\
\hline Myristica fragrans & $2 \%$ \\
\hline Sodium Lauryl sulphate & $0.2 \%$ \\
\hline Methyl paraben & $0.1 \%$ \\
\hline
\end{tabular}

1.4 Invitro antifungal assay of formulated hand wash gel using Camellia sinensis (Green tea) and Myristica fragrans (Nutmeg)

The cultures were grown in Sabourand's Dextrose Agar and incubated at room temperature for yeast species for $24-48$ hours, and five days for fungal growth. After incubation period was over, $0.1 \mathrm{ml}$ of microbial culture was seeded in $25 \mathrm{ml}$ molten Sabourand's Dextrose Agar butts, mixed, poured into sterile Petri plates and allowed to solidify. The wells were bored with $6 \mathrm{~mm}$ borer in seeded agar. $0.1 \mathrm{~g}$ of each hand cleanser gel sample was added in each well. Plates were kept at $10^{\circ} \mathrm{C}-15^{\circ} \mathrm{C}$ as a period of pre diffusion for 30 minutes. After normalization at room temperature, the plates were incubated at room temperature for $24-48$ hours for the growth of yeasts, and five days for fungal growth. After incubation period was over, the zone of inhibition was measured with the help of Hi-antibiotic zone scale. The formulated hand wash gel was further challenged with mixed inoculums of fungal strains along with the standard.

\section{Results and Discussion}

The present study was carried out to formulate Camellia sinensis and Myristica fragrans hydroethanolic combined extracts based hand wash using gel base as carriers. The formulation was prepared by using generally approved excipients that are compatible with any similar hand cleansing formulations. It was organoleptically evaluated to ensure product stability and performed in vitro antifungal test to prove its efficacy to act against fungal species.

Phytochemical screening of Camellia sinensis and Myristica fragrans was carried out for the presence of tannins, phenolic compounds, flavanoids, terpenoids, carbohydrates, glycosides, amino acids, and proteins. Results were noted in Table 1. Alkaloids interfere with cell division; hence the presence of alkaloids and other bioactive compounds account for its use as an antimicrobial agent. Terpenes or terpenoids are active against 
bacteria, fungi, virus, and protozoa. Terpenoids used to damage cell membrane of organisms. Flavanoids are group of chemicals found in varying amounts of foods, medicinal plants and cosmetics which have shown to exert potent antioxidant activity against the superoxide radical. Thus, the presence of bioactive compounds and the supporting studies accompanied with them depicts an impact for the use of Green tea and Nutmeg as active ingredients in the formulated hand wash gel.

Dr. Duke's Phytochemical and ethanobotanical database screened out all phytochemicals present along with their bioactive properties, and provides the maximum information of the known bio active compounds in Camellia sinensis and Myristica fragrans. It provides the details of biological and chemical activity, along with its appropriate dosage of administration and intensity factor. The antifungal activity of Camellia sinensis and Myristica fragrans extracts were tested against selected fungal species. The hydroethanolic extracts of Camellia sinensis and Myristica fragrans with $20 \mathrm{mg} / \mathrm{mL}$ concentration showed highest antifungal activity against Candida albicans when compared to other isolates. It was compared with standard antifungal agent Ketaconazole. Even though, Myristica fragrans (Nutmeg) found to be less active than Camellia sinensis, the bioactive molecule present in them rendered a good phyto-cosmeceutic property. The MIC values of hydroethanolic extracts of Camellia sinensis and Myristica fragrans with $20 \mathrm{mg} / \mathrm{mL}$ concentration were done by Broth Dilution method /and results were read spectrophotometrically at $600 \mathrm{~nm}$ and were tabulated in Table 2 and Table 3. If MIC values are more than $8 \mathrm{mg} / \mathrm{ml}$, then the result shows that the compound is active at very high doses and the fractions need to be analyzed to reach the final conclusion. If the MIC is less than $8 \mathrm{mg} / \mathrm{ml}$, where as an MIC of less than $1 \mathrm{mg} / \mathrm{ml}$ would indicate that compound is highly active.

Results were shown in Table 4 and in fig 1, 2, 3, 4, 5, 6, and 7 for In vitro antifungal assay of Camellia sinensis (Green tea) and Myristica fragrans (Nutmeg) based hand wash gel was performed against target fungal flora, and mixed fungal inoculum to determine its fungicidal efficacy. The hands exposed to contaminated inanimate objects are the primary mode of transmission of these multidrug-resistant pathogens and infections. The present study is an open, non- comparative prospective work. The gel base without any drugs has not shown any zone of inhibition. So it does not have any antimicrobial activity and the zones of inhibition of formulation found increasing with increase in herbal drug concentration. The components in the formulation are from herbal source and are very safe and eco-friendly. Green tea and nutmeg extracts imparts flavour, therapeutic, antiseptic, and antimicrobial and cosmeceutic properties.

Table 1- Results showing the Screening of Phytochemical constituents in extracts of Camellia sinensis (Green tea) and Myristica fragrans (Nutmeg)

\begin{tabular}{|c|c|c|c|}
\hline S.No & $\begin{array}{l}\text { Phytochemical } \\
\text { constituents }\end{array}$ & $\begin{array}{c}\text { Camellia sinensis (Green tea) } \\
\text { extracts }\end{array}$ & $\begin{array}{l}\text { Myristica fragrans } \\
\text { (Nutmeg) extracts }\end{array}$ \\
\hline 1. & Alkaloids & - & + \\
\hline 2. & Saponins & - & + \\
\hline 3. & $\begin{array}{l}\text { Tannins and } \\
\text { phenolic } \\
\text { compounds }\end{array}$ & + & + \\
\hline 4. & Flavanoids & + & + \\
\hline 5. & Terpenoids & + & - \\
\hline 6. & Carbohydrates & + & - \\
\hline 7. & Glycosides & + & + \\
\hline 8. & $\begin{array}{l}\text { Amino acids } \\
\text { and proteins }\end{array}$ & + & + \\
\hline
\end{tabular}


Table 2-Results showing the antifungal activity of Camellia sinensis and Myristica fragrans

\begin{tabular}{|c|c|c|c|c|c|c|c|}
\hline & & & \multicolumn{5}{|c|}{ Zone of Inhibition ( $\mathrm{mm}$ ) } \\
\hline Sample & $\begin{array}{l}\text { Extract } \\
\text { type }\end{array}$ & $\begin{array}{l}\text { Concentrati } \\
\text { on used }\end{array}$ & 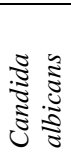 & 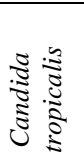 & 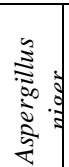 & 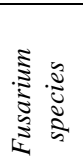 & 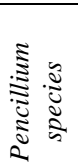 \\
\hline \multirow{4}{*}{$\begin{array}{c}\text { Camellia } \\
\text { sinensis } \\
\text { (Green tea) }\end{array}$} & \multirow{3}{*}{$\begin{array}{l}\text { Hydro } \\
\text { ethanolic }\end{array}$} & $20 \mathrm{mg} / \mathrm{mL}$ & 23 & 14 & 16 & 19 & 19 \\
\hline & & $10 \mathrm{mg} / \mathrm{mL}$ & 16 & 12 & 15 & 17 & 18 \\
\hline & & $5 \mathrm{mg} / \mathrm{mL}$ & 7 & $\begin{array}{c}\text { No } \\
\text { zone }\end{array}$ & 8 & $\begin{array}{l}\text { No } \\
\text { zone }\end{array}$ & 6 \\
\hline & \multirow{3}{*}{$\begin{array}{l}\text { Hydro } \\
\text { ethanolic }\end{array}$} & $20 \mathrm{mg} / \mathrm{mL}$ & 22 & 16 & 15 & 19 & 16 \\
\hline \multirow{2}{*}{$\begin{array}{l}\text { Myristica } \\
\text { fragrans } \\
\text { (Nutmeg) }\end{array}$} & & $10 \mathrm{mg} / \mathrm{mL}$ & 16 & 12 & 13 & 15 & 14 \\
\hline & & $5 \mathrm{mg} / \mathrm{mL}$ & 8 & 5 & 9 & $\begin{array}{c}\text { No } \\
\text { zone }\end{array}$ & 12 \\
\hline Ketoconazole & - & $15 \mathrm{mcg}$ & 23 & 20 & 12 & 14 & 18 \\
\hline
\end{tabular}

Ketoconazole $(15 \mu \mathrm{g})$ - Susceptible $>28 \mathrm{~mm}$, Intermediate $21-27 \mathrm{~mm}$, Resistant $<20 \mathrm{~mm}=$

Table 3-Minimum Inhibitory Concentration (MICs) of extracts of Camellia sinensis (Green tea) and Myristica fragrans (Nutmeg)

\begin{tabular}{|c|c|c|c|c|c|c|c|}
\hline Sample & Organism & \multicolumn{6}{|c|}{ Dilution (read at $600 \mathrm{~nm}$ ) } \\
\hline \multirow{2}{*}{$\begin{array}{c}\text { Camellia sinensis (Green } \\
\text { tea) }\end{array}$} & \multirow{2}{*}{$\begin{array}{l}\text { Candida } \\
\text { albicans }\end{array}$} & 1 & 11 & 111 & $1 \mathrm{~V}$ & $\mathrm{~V}$ & V1 \\
\hline & & 0 & 0 & 0 & 0.007 & 0.05 & 0.071 \\
\hline $\begin{array}{l}\text { Myristica fragrans } \\
\text { (Nutmeg) }\end{array}$ & $\begin{array}{l}\text { Candida } \\
\text { albicans }\end{array}$ & 0 & 0 & 0 & 0.009 & 0.072 & 0.089 \\
\hline
\end{tabular}

Table 4-Invitro antifungal activity assay of Camellia sinensis (Green tea) and Myristica fragrans (Nutmeg) based hand wash gel

\begin{tabular}{|c|c|c|c|c|c|}
\hline \multicolumn{2}{|c|}{} & \multicolumn{3}{|c|}{ Zone of Inhibition (mm) } \\
\hline S.No & Microorganisms & $\begin{array}{c}\text { Formulated } \\
\text { Handwash } \\
\text { gel }\end{array}$ & SLS & Gel base & Std. \\
\hline 1. & Candida albicans & 28 & No Zone & No Zone & 20 \\
\hline 2. & Candida tropicalis & 20 & 5 & No Zone & 10 \\
\hline 3. & Aspergillus niger & 20 & 1 & No Zone & 12 \\
\hline 4. & Fusarium species & 30 & No Zone & No Zone & 11 \\
\hline 5. & Pencillium species & 24 & 4 & No Zone & 16 \\
\hline 6. & $\begin{array}{c}\text { Mixed fungal } \\
\text { culture }\end{array}$ & 22 & No Zone & No Zone & 12 \\
\hline
\end{tabular}

Std. - indicates standard antifungal agent (Ketaconazole),

Formulation- Gel base + Camellia sinensis ( $2 \%$ concentration)+ Myristica fragrans ( $2 \%$ conc.)

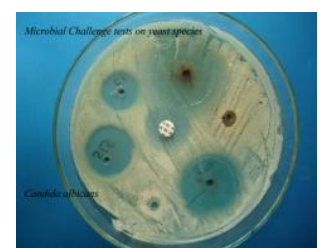

Fig: Candida albicans

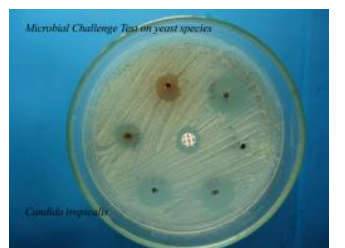

Fig: Candida tropicalis

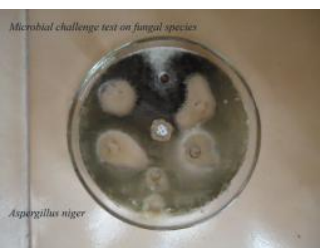

Fig: Aspergillus niger

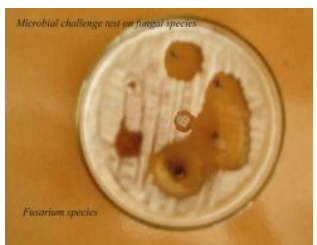

Fig: Fusarium species 


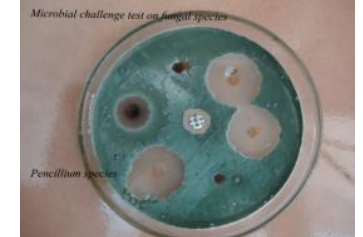

Fig: Pencillium species

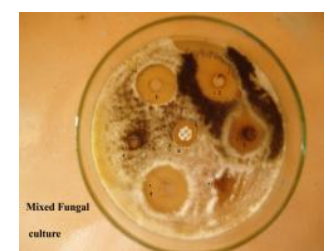

Fig: Mixed fungal species

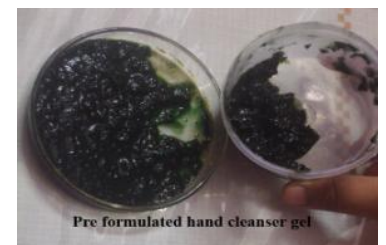

Fig: Formulated hand wash gel

\section{Conclusion}

The present work was designed with the objective to formulate a hand wash gel with Camellia sinensis and Myristica fragrans as active ingredients. For this, Camellia sinensis and Myristica fragrans were collected from different sources, processed and stored under proper conditions, and hydroethanolic extracts were prepared. Invitro antifungal assay was performed. Based on the results, hydroethanolic extracts of Camellia sinensis and Myristica fragrans were subjected for phytochemical screening. Using Dr. Duke's phytochemical and ethanobotanical databases, the bioactive compounds were pooled out to get the thorough knowledge of the bioactive compounds suitable to be used as ingredients in the formulated hand wash gel. Isolation of microbial flora from different contaminated inanimate sites indicates the requirement of hand washing with effective antiseptic and therapeutic coverage without any side effects. The main ideology behind combining the plant materials was to observe the additive effect of the active constituents of different plants. The combination proves to be beneficial with the results of antifungal assay. Development of new hand wash gel like products are becoming popular than the traditional soap and water due to their ability to provide instant protection by reducing transient microbial flora on the hands exposed to contaminated inanimate objects.

\section{References}

[1]. Mitscher, L.A., Drake, S., Gollupudi, S.R and Okuate, S.K.1978. A modern look at folklonic use of antiinfective agents, J. Ethanopharmacol.50: 1025-1040.

[2]. Susheela Raghavan.2003. Handbook of seasonings and flavoring 2ndEdition.

[3]. H.O. Edeoga, D. E. Okwu and B.O Mbaebie ., Phytochemical constituents of some Nigerian medicinal plants, African Journal of Biotechnology , 2005; Vol. 4 (7), pp. 685-688,

[4]. Werkhoven, J., 1978 Tea processing Ist Edtn. FAO, Rome (Italy).

[5]. Lu Y-P, Lou Y-R, Xie J-G, et al. 2002 Topical applications of caffeine for (-) epigallocatechin gallate (EGCG) inhibit carcinogenesis and selectively increase apoptosis in UVB-induced skin tumors in mice. Proc Natl Acad Sci USA;99: 12455-12460.

[6]. de Guzman C.C., and Siemonsma, J.S., (Editors).. Plant Resources of South-East Asia No.13. Spices 1999Backhuys Publishers, Leiden, The Netherlands.

[7]. Weiss E.A, Spice Crops 2002. CABI Publishing, CABI International, UK.

[8]. Sridhar, S.R., Rajagopal, R. V., Rajavel, R., Masilamani, S., Narasimham, S., 2003. Antifungal activity of some essential oils. J Agric Food Chem, ;51:7596-7599.

[9]. Takikawa, A., Abe, K., Yamamoto, M., Ishimaru, S., Yasui, M., Okubo, Y., Yokoigawa, K., 2002. Antimicrobial activity of nutmeg against Escherichia coli O157. Journal of Bioscience and Bioengineering; 94 (4:315-320).

[10]. Rico, M.J., 2000. Rising drug costs: the impact on dermatology. Skin Therapy Lett; 5:1-2, 510

[11]. Riju, A., Sithara, K., S.S., Shamina, A., Eapen S.J., 2009. In Silico Screeening Major Spice Phytocehmicals for their Novel biological activity against Escherichia coli O157

[12]. Ghouse, A.K.M.; Yunus, M.; Farooqui, F. \& Sabir, D., A simple maceration technique for the separation of sieve elements from the barks of woody plants. Current Science, 1974; 43: 424-425.

[13]. Evans, W.C., Trease and Evans Pharmacognosy. 1996. Harcourt Brace \& Co; Asia, Singapore; 14:273.

[14]. Kirby MDK, Sherris JC, Turck M. Antibiotic susceptibility testing by standard single disc diffusion method. Am J Clin Pathol 1966; 45: 493-496.

[15]. National Committee for Clinical Laboratory Standards.Reference method for broth dilution antifungal susceptibilitytesting of filamentous fungi. Approved standard M38-A. Wayne, PA: NCCLS, 2002

[16]. Reddy C. S, Rammohan T, Madhu N, Divakar M.C, Transdsermal diffusion studies of a poly herbal ointment and its topical therapy, Ancient Sci Life. 1998; 14(\&2): 76-85 15

[17]. Pai M.R, Acharya L.D, Udupa N, Evaluation of antiplaque activity of Azadirachta indica leaf extract gel - a 6-week clinical study, J Ethanopharmacol. 2004; 90: 99-103. 16

[18]. Gupta G.D, Gaud R.S, Release rate of nimesulide from different gellants. Indian J. Pharma Sci. 1999; 61 (4): 227-30. 